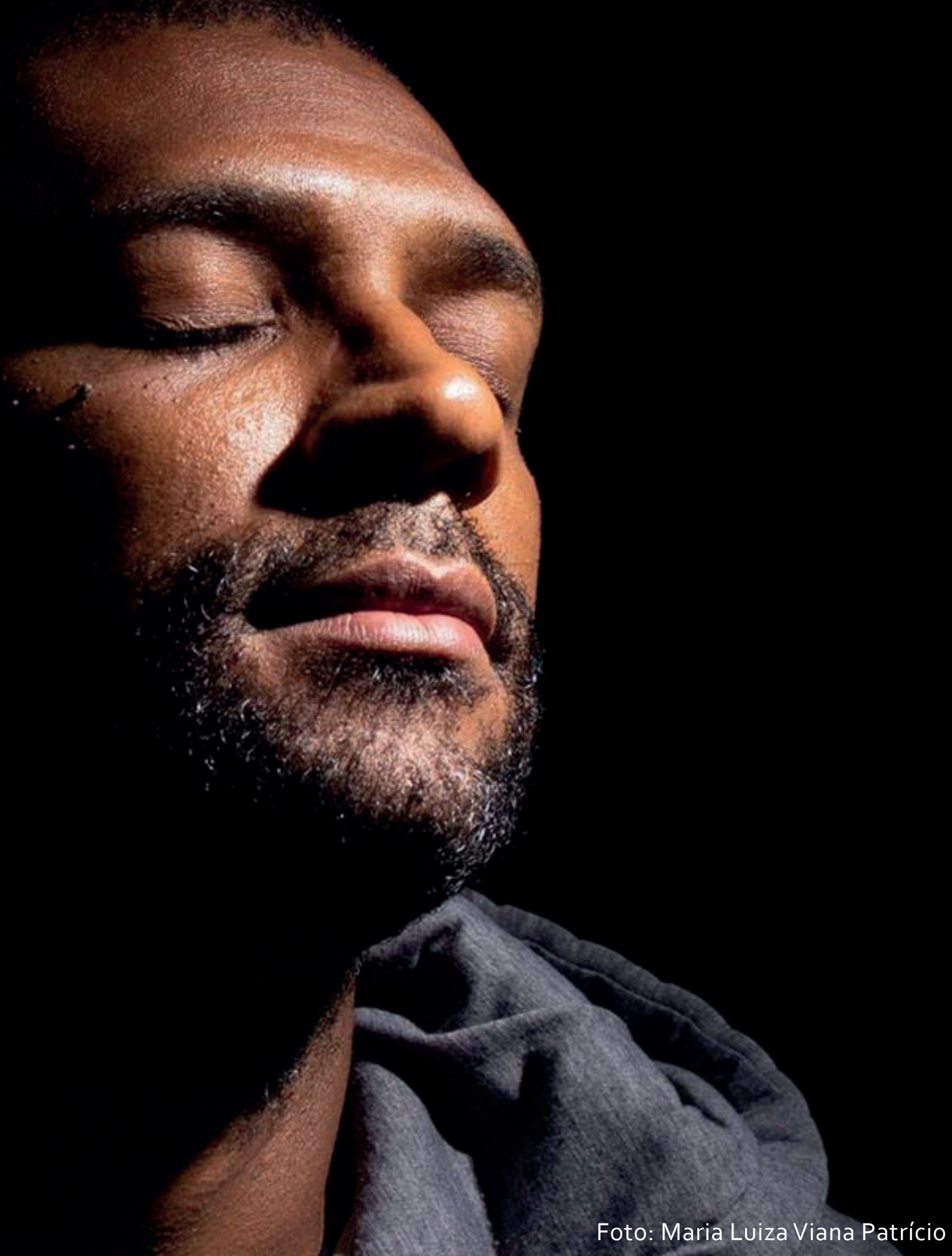

\title{
literatura e afetos
}

\section{ENTREVISTA COM FERNANDO ROCHA}

Literature and affections: interview with Fernando Rocha

\section{Rafaela Alves Fernandes ${ }^{1}$}

$1 \quad$ Licenciada em Artes Cênicas pela Faculdade Paulista de Artes e bacharela em História da Arte pela Universidade Federal de São Paulo. É professora titular de Arte no ensino fundamental e médio pelas Secretarias Municipal e Estadual de Educação de São Paulo. E-mail: rafa_a_fernandes@hotmail.com 
Fernando Rocha é paulistano, graduado em Letras, professor na rede municipal de ensino de São Paulo, fotógrafo e autor dos livros Sujeito sem verbo, Os Laços da fita, Afetos e Pouca Pele - este último publicado recentemente. Possui textos em diversos sites, como: Mallarmagens, Amaité Poesias \& Cia, Diversos e Afins, Revista Gueto, Incomunidade, Letras Inacabadas e Letras et Cetera.

Nesta entrevista, gentilmente concedida para a Opiniães via correspondência eletrônica no mês de maio, Fernando Rocha expõe suas ideias acerca da intrincada relação entre a literatura e os afetos, desde o processo criativo até a recepção da obra pelos leitores.

\section{entrevista}

Em Afetos, livro publicado em 2016, há um conto denominado Afeto sem o filtro da linguagem, no qual se lê: "As palavras que eu tinha aprendido até então perderam o sentido que nunca tiveram, já que o silêncio é a mãe de todas as línguas e a língua transformada em linguagem só produz barulho sem significação". Em que medida a linguagem representa um empecilho à expressão dos afetos?

Sendo bem honesto, eu não sei definir, apenas sinto isso. Nós, enquanto espécie, temos ouvido e lido cada vez pior. Talvez com todas as revoluções com as palavras, feitas no século $X X$, não haja muito o que fazer, apenas exercitar a honestidade. Como alguém pode escrever o beijo afetuoso de uma avó? Um beijo apaixonado? Clarice Lispector entendeu o empecilho da linguagem. Alguém consegue explicar por meio da linguagem um livro como 
Água viva? O silêncio é uma ambição antiga dos escritores. A tentativa de escrevê-lo é o eterno fracasso do qual não conseguimos fugir.

Em As palavras e as coisas, Michel Foucault discorre sobre os limites da representação, especialmente linguística, quando já não é mais possível crer que a linguagem constitui uma rede incolor a partir da qual o mundo se ordena. A linguagem exerce aqui um papel central, uma vez que é através dela que a nossa percepção sobre o mundo é acessada. Em seu modo de ver, como opera essa relação entre representação e linguagem no interior da escrita literária?

Penso que a linguagem vem perdendo essa hegemonia. Na ponte entre a nossa percepção sobre o mundo, o mundo nos sufoca com uma avalanche de imagens. Embora a maior parte delas ainda não seja pensada. A literatura mais potente explode essa representação; a escrita literária que é mais aguda, tenta saltar a dicotomia proposta pelo Saussure e migrar direto para o sentir. O primeiro parágrafo de Memórias do Subsolo, vários momentos da obra da Márcia Barbiérie e a senhora Lispector são exemplos desta usurpação.

Esta crise da representação, não apenas na literatura, mas na arte do século $X X$, cedeu espaço a que, na sua opinião?

Ao vazio, não o dos niilistas, mas ao que os chineses já tinham falado sobre, séculos antes dos filósofos franceses. Mas a liberdade é uma prisão da qual ainda temos dificuldade para traçar um plano de fuga. 
Ao passo que pensamos a literatura pelo viés do afeto, pode-se dizer que a libertamos do império do sentido, deslocando-a para a experiência física? Como você pensa a relação entre literatura e corpo?

Eu não penso sobre isso e nem sei se é possível formular um encadeamento lógico sobre o tema. Quando li Crime e castigo, senti todas as febres do Raskólnikov. O poeta Marcelo Ariel tem um texto no qual narra a internação da Clarice Lispector por conta da queimadura, e, ao meu ver, toca neste ponto.

De que modo os afetos podem irromper em uma atividade tão intelectual como a leitura da literatura?

A gente vem vivendo maquinalmente há um tempão. Pode ser que o problema não esteja no momento da leitura ou da escrita, mas no antes de tais ações. Quando paramos para escrever ou ler, botamos muito toda a nossa forma de ser na realização dessas ações.

Os afetos possuem uma dimensão política? Qual a potência do afeto em seu trabalho?

As eleições do ano passado comprovam toda a dimensão política dos afetos.

Em meu trabalho, o afeto é sempre uma intenção. 
Em seus livros, a percepção sensível em torno da exterioridade do mundo é traduzida em descrições que capturam instantâneos fugidios àqueles que passam pela vida sem contemplá-la. Nesse sentido, pode-se dizer que em sua escrita a literatura funciona como um meio de contemplação estética do mundo? Em caso afirmativo, de que "estética" estamos falando?

Não acredito numa contemplação estética do mundo, acho frio como poesia concreta e algumas canções da tropicália. Um tipo de arte que exige manual para ser contemplada, fazendo valer o que o John Lennon disse em Beautiful boy: "A vida é o que acontece/ Enquanto você fica parado fazendo planos." Se pegarmos a obra do Guimarães Rosa, toda contemplação estética serve para depois ser enxugada e funcionar como ferramenta para a construção de uma ponte para o simples, que nunca é simplório.

Este diálogo sobre literatura e afetos me remete ao trecho de uma carta que Franz Kafka escreveu: "Acho que só devemos ler a espécie de livros que nos ferem e nos trespassam (...) Precisamos de livros que nos afetam como um desastre, que nos magoam profundamente, como a morte de alguém a quem amávamos mais do que nós mesmos, como ser banido para uma floresta longe de todos. Um livro tem que ser como um machado para quebrar o mar de gelo que há dentro de nós"². Você acredita que a literatura é capaz de nos afetar dessa maneira? Há algum livro ou escritor que tenha lhe afetado de forma semelhante?

2 Franz Kafka, carta a Oscar Pollak, 1904. 
Eu só posso responder essa questão relembrando algumas experiências como leitor mediano que sou. Quando li De mim já não se lembra, do Luiz Ruffato, $A$ Puta, da Márcia Barbiéri e a trilogia inicial do Juliano Garcia Pessanha, senti exatamente o que Kafka escreveu na carta.

Com frequência, você cita escritores brasileiros contemporâneos como Márcia Barbiéri, Juliano Garcia Pessanha, Daniel Lopes, Luiz Ruffato, Marcelo Ariel, entre tantos outros. Você enxerga algo em comum nas obras desses autores ou em seus processos de criação e circulação?

Tive um professor na graduação com quem, de fato, pouco dialoguei, mas, numa aula, ele lançou uma provocação: gostaria de ver mais teses sobre autores vivos. Carreguei isso comigo. Uma possível maneira de tentar entender o tempo estranho em que vivemos é ler as obras dos artistas que andam por aí e partilham a experiência do mesmo tempo que nós. Eu gosto muito de todos os autores que você citou na questão. De alguma forma, todos eles me influenciam. Não enxergo algo que os una em construção literária e circulação.

Quais escritores brasileiros exercem maior influência sobre o seu trabalho?

Além dos citados acima, a senhora Lispector, Manuel Bandeira, Akira Yamasaki, as letras das canções do Jair Naves, Mario Quintana e Lisa Alves. 
Paralelamente ao seu trabalho como escritor, você desenvolve experimentações com a linguagem fotográfica. Além disso, seus textos são permeados de imagens, imagens que evocam outras e outras imagens. Quais relações você enxerga entre a literatura e a fotografia? Qual a importância das imagens em seus textos?

A primeira relação que enxergo entre as duas linguagens é a proximidade da fotografia de rua com a crônica. Não sei dirigir, por isso ando por aí, às vezes a esmo, com a falsa impressão de que estou atravessando todo mundo e, ao mesmo tempo, sendo atravessado. Nessas caminhadas, às vezes enxergo uma imagem que fica aqui dentro, me incomodando, até que eu tente traduzir/inventar o que vi em palavras. Penso que as imagens convidam a atenção para contemplá-las. É uma decisão mergulhar nelas ou dar a mão ao automatismo e seguir em frente.

Tanto na fotografia quanto em seus textos, é comum o olhar se deter no detalhe, no pequeno e mais imperceptível, no invisível... Poderia comentar acerca deste traço de sua poética?

Só consigo responder a isso evocando um trechinho de $O$ espelho, do Rosa: "Quando nada acontece, há um milagre que não estamos vendo".

Em seu último livro, Pouca Pele, lançado no ano passado, você parece explorar o caráter paradoxal dessa membrana, que é, a um só tempo, casca que protege o ser do mundo, mas que representa, também, um limite 
a ser transgredido. Você poderia comentar acerca da noção de "pouca pele"? O que ela representa para você? Pode-se dizer que o escritor é um sujeito que possui pouca pele

Pouca pele é estar vulnerável, afetado por tudo que nos cerca numa pequena volta pelo bairro, como diz a epígrafe deste texto, retirada de uns versos do Sá-Carneiro:

"- Triste de Mim, que vim de Alma pra rua,

E nunca a poderei deixar em casa..."

Para mim, é o jeito de estar no mundo, não só como escritor, mas como humano. A escrita é invadir o espaço do outro, apropriar-se e dar novos nortes para ele.

No mesmo livro, há um conto chamado "Sábado", em que se lê: "Perco meu tempo escrevendo, ainda há milhares de analfabetos em meu país, a subjetividade está sendo eliminada, por meio da lei, nos tiram o direito de ficar em paz. Nos enchem com um cansaço que não passa, um futuro já preenchido por afazeres e preocupações insolúveis". Por que escrever mesmo em meio a tantas tragédias? Para quem você escreve?

Na entrevista que o Marcelo Ariel dá ao extinto Entrelinhas, ele diz que a linguagem é uma doença. Concordo com ele. E a escrita literária é o estágio mais avançado dessa patologia. Não está dentro do querer de quem a faz, pois ela acontece como a convulsão de epilético, o espasmo de um orgasmo, o frio na barriga que sentimos quando vítimas de um susto. Isso me atrai em 
Raduan Nassar, por exemplo, mais do que as obras que ele produziu. Como calar o chamado?

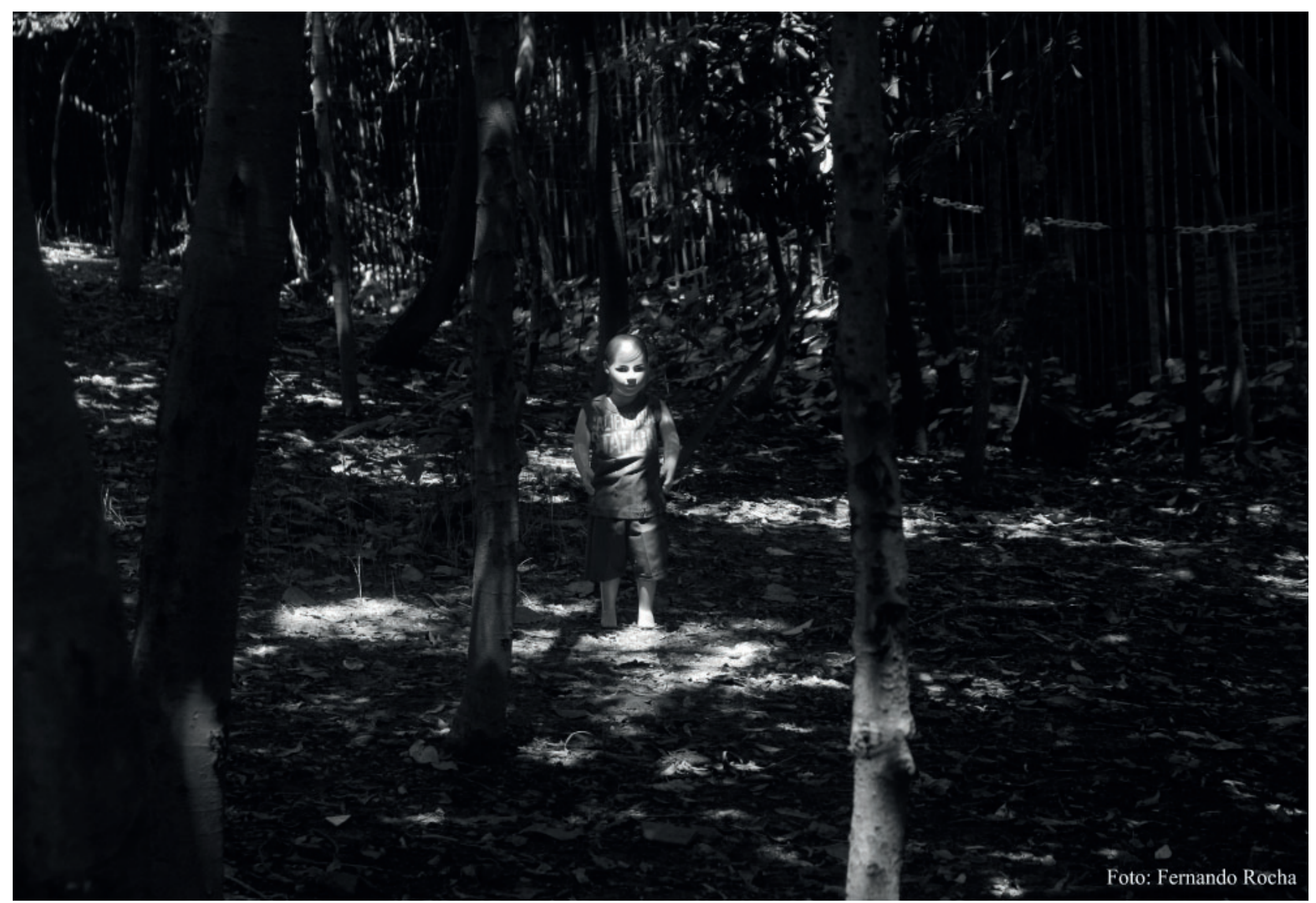

Em vários de seus textos, há referências a situações do cotidiano escolar. Ainda há espaço para a subjetividade na escola? Em sua opinião, onde reside a potência da escola hoje?

A escola é uma das maiores assassinas de subjetividade que conheço. Aqueles que chamam e entendem como bom aluno, é alguém fadado ao mecanicismo, uma boa mola na engrenagem. A potência da escola reside em não se pensar maior do que a sociedade na qual está inserida; assim, poderá pensar nas brechas e não nas bordas do aparente do todo. 
Você acompanha, há algum tempo, o trabalho de resistência artística de grupos da zona leste de São Paulo, que, apesar de tudo, sobrevivem. Você poderia falar um pouco sobre essa experiência? Quais as principais problemáticas enfrentadas por aqueles que fazem arte e literatura na periferia de São Paulo?

É impressionante como a turma produz - muito - e muitos nunca ganharam um centavo dos editais. Com vaquinhas, produzem livros, álbuns musicais. Destaco aqui a atuação da Casa Amarela, capitaneada por Akira Yamasaki, Sueli Kimura e Escobar Franelas. Há um movimento muito interessante de música no Itaim Paulista, com bandas que botam o equipamento na calçada e fazem a coisa acontecer. Velhos Bohemios e O Verso são dois exemplos. O maior problema da arte feita por membros da classe trabalhadora é a conciliação entre o trabalho pragmático e o trabalho criativo. Por conta do desgaste, muitos desistem da arte, afinal, a gente precisa comer, quer tomar banho quente e ter um teto para se alojar. Ninguém se alimenta com conceitos.

De acordo com Deleuze, o escritor é aquele que já viu muito. Você concorda com a afirmação?

Deleuze é uma figura interesante, mas os tais Deleuzeanos... Sim, concordo com ele, o escritor é como aquele andróide de Blade Runner, no monólogo famoso. 